\title{
Performance of Grid-Connected Solar Photovoltaic Systems with Single-Tuned and Double-Tuned Harmonic Passive Filters
}

\author{
Murukwadura A. Mendis ${ }^{1}$, Ahmed F. Zobaa ${ }^{1}$, Ioana Pisica ${ }^{1}$, and Shady H. E. Abdel Aleem ${ }^{2}$
}

\begin{abstract}
The generated solar photovoltaic power can be stand-alone or grid-connected. In both systems, power quality issues arise and can affect the network. The harmonic distortions can affect the system significantly if they are not mitigated. This paper presents the performance of grid-connected solar photovoltaic systems with single-tuned and double-tuned filters for harmonics mitigation. The design aspects of each filter are presented and discussed. The simulation results are analyzed and validated using ETAP software.
\end{abstract}

Keywords: Grid-connected systems, Passive filters, Photovoltaic energy systems, Power quality, Power system harmonics, Tuned filters.

\section{Introduction}

Throughout the last decades, world energy generation using high greenhouse emission gas sources has been increased with the catastrophic warming of the earth. The majority of those energy comes from burning coal, gas, and fossil fuels around the world. Right now, a lot of studies around the world are going on to find better ways of generation of energy to reduce the undesirable impacts of conventional fossil fuel-based technologies. As a result of progressive advance in technology, policy, and finance; the solar power generation is currently becoming more reliable, efficient, and commercially competitive source of energy [1], [2]. Nowadays, the renewable energy plays a significant role in electrical power generation and among them, the solar photovoltaic (PV) energy plays a major role in the electrical power generation as it is clean and green energy product as well as its technical benefits [3], [4].

Each source of energy has unique requirements and benefits. However, the sun, mother of all energy resources, is a uniquely clean and infinite source of free energy that has brought a global potential for rapid growth of photovoltaic power generation with different application technologies. At present, solar PV power generation has taken a remarkable place in the electrical power generation, and it is almost keeping an average of $25 \%$ to $30 \%$ of the annual growing rate in most of the developed countries around the world. Nevertheless, these renewable energy generation units are connected to the power system by different ways depending on the real source availability on the ground. Further with the aspect of achieving high security and reliability of the power system, the renewable sources interconnects to the power networks. As a result, the current power system becomes not a one-way route of power generation [5].
This scenario of power systems becomes a challenging task to maintain a good power quality (PQ) of the network. Before the 1960s, there was no much interest toward PQ, but nowadays most of the power system equipment are more sensitive to $P Q$ variations, especially power electronic equipment and microprocessor-based equipment. The growing use of more electronic equipment will also add more and more PQ problems to the power system [6], [7].

Harmonic distortion is one of the significant PQ problems. When the electrical energy is being generated using solar PV panels, harmonics will be created as power electronics-based equipment is used to convert the DC power into AC power. The increased harmonic distortion will reduce the efficiency of the system. Thus, it is important to measure these harmonics, and then take corrective actions to reduce their negative impacts on the system [8].

Still, most industrial applications use the harmonic passive facilities for harmonics mitigation and reactive power compensation for their simplicity, reliability, and their economic aspects compared with other harmonics reduction methods [9]. During the last decade, more studies have been done on different passive filter schemes for harmonics mitigation in both stand-alone and gridconnected solar PV systems. In its broad sense, these studies usually present the basic structure and components of the PV system, the causes of harmonics and their consequences. Then they discuss how to improve the power quality of the system and protect the equipment connected to the system under study using a different combination of passive harmonic filters [4], [10]- [13].

In this paper, tuned filters represented by single-tuned and double-tuned passive filters are introduced for enhancing the performance of a harmonic distorted gridconnected PV system. The level of harmonic distortion is 
measured and compared with the standard harmonic levels reported in the international standards, i.e. IEEE Standard 519-2014 [14]. The design and mathematical formulation of both passive filter configurations are presented, advantages and disadvantages of the doubletuned filters compared to the single-tuned filters in a PV system is discussed to achieve the final outcomes. In addition, the grid-connected PV system, nonlinear loads, and the passive filters are modeled and simulated using ETAP software.

\section{Single-tuned Filter Design}

This section presents the design considerations of a single-tuned passive filter. A single-tuned filter consists of a series combination of the resistance $\left(R_{S}\right)$, inductor $\left(\mathrm{L}_{\mathrm{S}}\right)$, and capacitor $\left(\mathrm{C}_{\mathrm{S}}\right)$ as shown in Fig. 1.

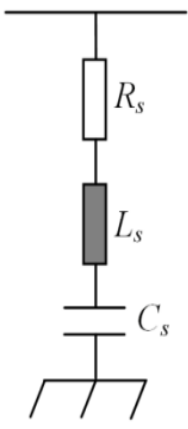

(a)

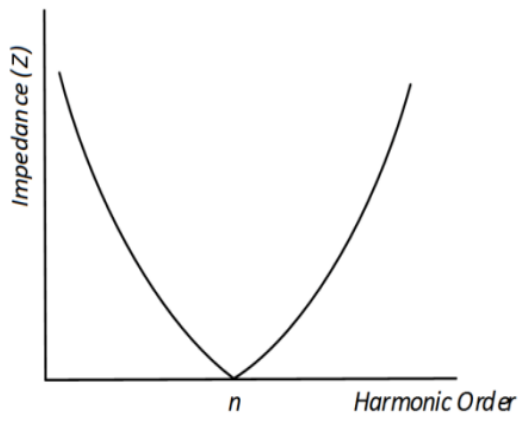

(b)
Fig. 1. Single-tuned filter configuration (a) Its equivalent circuit

(b) Its impedance $(Z)$ versus the harmonic order (n)

The principal aim of this filter is to create a low impedance path at a particular harmonic frequency to divert the corresponding harmonic. As shown in Fig. 1, one can notice that the total impedance $(\mathrm{Z})$ of the filter will be minimum at a particular harmonic frequency, i.e. $n * f_{1}$ by making the inductive and capacitive reactance values equal at this tuning frequency, where $n$ is the harmonic order and $f_{1}$ is the fundamental frequency. The total filter equivalent impedance $Z_{S}(\omega)$ as a function of the harmonic angular frequency $\omega$ is given in (1).

$Z_{S}(\omega)=R_{S}+j\left(\omega L_{S}-\frac{1}{\omega C_{S}}\right)$

Generally, the capacitor $C_{\mathrm{S}}$ is determined for a known reactive power compensation required to improve the initial power factor to a desired initial power factor value in the power system. In particular, the required value of the capacitor can be calculated from Equation (2) at a specific harmonic order, at which the filter shall resonate [10], [15].

$C_{S}=\frac{Q_{c}}{\left(2 \pi f_{1}\right) V^{2}}\left(1-\frac{1}{n^{2}}\right)$ where $V$ is the rms value of the rated load voltage. The fundamental value of the filter inductor $\left(\mathrm{L}_{S}\right)$ is given in terms of $C_{\mathrm{S}}$ and the tuning frequency $\left(f_{\mathrm{n}}\right)$, as follows:

$$
L_{S}=\frac{1}{\left(2 \pi f_{n}\right)^{2} C_{s}}
$$

At the tuning frequency $\left(f_{n}\right), Z_{S}$ will become resistive, and it will equal to the filter resistance $\left(R_{S}\right)$, or zero for an ideal filter with high-quality factor circuit.

The value of $R_{\mathrm{S}}$ can be calculated, as given in Equation (4), at a given quality factor (q), which is defined as the ratio of the inductive reactance to the resistance $\left(\omega_{n} L_{S} / R\right)$ at the resonant frequency. In most cases, the value of $q$ varies between 20 and 100 . When $q$ is high, the filter will give the best harmonics attenuation but with higher filter cost [10], [15].

$R_{S}=\frac{\left(2 \pi f_{n}\right) L_{S}}{q}$

\section{Double-tuned Filter Design}

For the design of a double-tuned passive filter, a secondary set of an inductor $\left(\mathrm{L}_{\mathrm{P}}\right)$ and a capacitor $\left(\mathrm{C}_{\mathrm{P}}\right)$ will be included as shown in Fig. 2. The conventional double-tuned filter consists of a series and a parallel resonance circuits. This filter eliminates two specific harmonic frequencies, $n_{1} * f_{1}$ and $n_{2} * f_{1}$, where $n_{1}$ and $n_{2}$ represent the tuned harmonic orders. The total filter equivalent impedance $Z_{T}(\omega)$ as a function of the harmonic angular frequency $\omega$ is given in Equation (5) in terms of the series impedance $Z_{S}(\omega)$ that represent the series resonant circuit, and the parallel impedance $Z_{P}(\omega)$ that represent the parallel resonant circuit of the filter. In the literature, two parallel single-tuned filters can be considered as equivalent double-tuned filter model as shown in Fig. 3 in order to determine the parameters of the double-tuned filter [16].

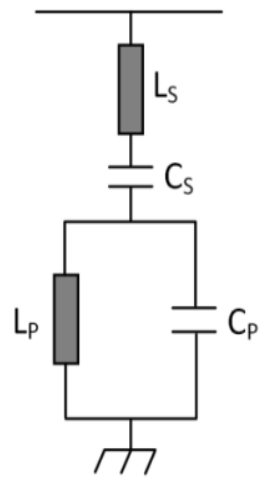

(a)



(b)
Fig. 2. Double-tuned filter configuration (a) Its equivalent circuit

(b) Its impedance $(Z)$ versus the harmonic order (n) 


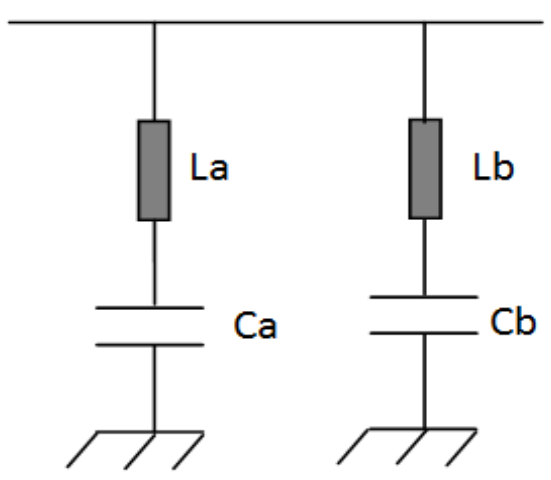

Fig. 3. Parallel two single-tuned filters

$Z_{T}(\omega)=Z_{S}(\omega)+Z_{P}(\omega)$

where,

$Z_{S}(\omega)=j \omega L_{S}+\frac{1}{j \omega C_{S}}$

$Z_{P}(\omega)=\left(j \omega C_{P}+\frac{1}{j \omega L_{P}}\right)^{-1}$

Accordingly, one can find the total filter equivalent impedance $Z_{T}(\omega)$ as a function of the harmonic angular frequency $\omega$ is given in Equation (8).

$Z_{T}(\omega)=\left(j \omega L_{S}+\frac{1}{j \omega C_{S}}\right)+\left(j \omega C_{P}+\frac{1}{j \omega L_{P}}\right)^{-1}$

Regarding the two single-tuned parallel filters given in Fig. 3, they resonate at frequencies $\omega_{\mathrm{a}}$ and $\omega_{\mathrm{b}}$ which can be expressed as follows:

$\omega_{a}=\frac{1}{\sqrt{L_{a} C_{a}}}$

$\omega_{b}=\frac{1}{\sqrt{L_{b} C_{b}}}$

Ref. [16] used the analogy of the two equivalent circuits of the double-tuned filters that are shown in Figs. 2 and 3 to calculate the parameters of the filter as follows:

$C_{S}=C_{a}+C_{b}$

$L_{S}=\frac{1}{C_{a} \omega_{a}^{2}+C_{b} \omega_{b}^{2}}$

$\omega_{S}=\frac{1}{\sqrt{L_{S} C_{S}}}$

$\omega_{P}=\frac{\omega_{a} \omega_{b}}{\omega_{S}}$

where $\omega_{S}, \omega_{\mathrm{p}}$ are the resonant frequencies of the series $L_{S}$ and $C_{S}$ circuit, and the parallel $L_{P}$ and $C_{P}$ circuit, respectively. Hence, one can find $L_{P}, C_{P}$ as follows:

$L_{P}=\frac{\left(1-\frac{\omega_{a}^{2}}{\omega_{S}^{2}}\right)\left(1-\frac{\omega_{a}^{2}}{\omega_{P}^{2}}\right)}{C_{1} \omega_{a}^{2}}$

$$
C_{P}=\frac{1}{L_{P} \omega_{P}^{2}}
$$

\section{The System under Study: Modeling and Simulation}

Fig. 4 shows the system under study with a connected photovoltaic system (PV) at bus 1. Different types of linear and nonlinear loads are introduced at different buses to simulate and analyze the performance of the overall system and to evaluate the harmonic levels and distortions.

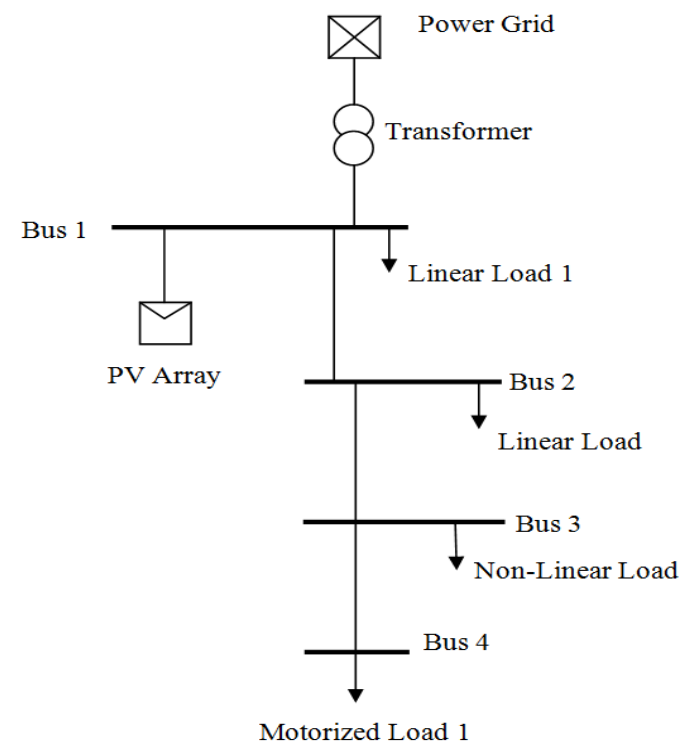

Fig. 4. Single-line diagram of the system under study

The solar technology used is Mono-Crystalline, manufactured by the Philadelphia Solar with the product number of PS-M72H [17]. The used inverter model is Sunny Central (630 MV), built by Sunny Central [17]. As shown in Fig. 4, a 20 MVA transformer connects the 60 $\mathrm{kV}$ system to the $20 \mathrm{kV}$ system.

The transformer parameters, the transmission line parameters, the technical data of loads, and the technical data of the transmission system are given in Tables I to IV, respectively.

TABLE I

TRANSFORMER PARAMETERS

\begin{tabular}{cc}
\hline \hline Parameters & Values \\
\hline Rated power & $20 \mathrm{MVA}$ \\
Rated voltage HV side & $60 \mathrm{kV}$ \\
Rated voltage LV side & $20 \mathrm{kV}$ \\
Copper losses & $102.76 \mathrm{~kW}$ \\
No-load losses & $10.96 \mathrm{~kW}$ \\
\hline
\end{tabular}


TABLE II

TRANSMISSION LINE PARAMETERS

\begin{tabular}{|c|c|c|c|}
\hline From bus & To bus & Resistance $(\Omega)$ & Reactance $(\Omega)$ \\
\hline 1 & 2 & 0.1256 & 0.1404 \\
\hline 2 & 3 & 0.1912 & 0.0897 \\
\hline 3 & 4 & 0.4874 & 0.2284 \\
\hline \multicolumn{4}{|c|}{$\begin{array}{c}\text { TABLE II } \\
\text { TRANSFORMER PARAMETERS }\end{array}$} \\
\hline \multicolumn{3}{|c|}{ Parameters } & Values \\
\hline \multicolumn{3}{|c|}{ Rated power } & 20 MVA \\
\hline \multicolumn{3}{|c|}{ Rated voltage HV side } & $60 \mathrm{kV}$ \\
\hline \multicolumn{3}{|c|}{ Rated voltage LV side } & $20 \mathrm{kV}$ \\
\hline \multicolumn{3}{|c|}{ Copper losses } & $102.76 \mathrm{~kW}$ \\
\hline \multicolumn{3}{|c|}{ No-load losses } & $10.96 \mathrm{~kW}$ \\
\hline
\end{tabular}

TABLE III

TECHNICAL DATA OF LOADS

\begin{tabular}{cccc}
\hline \hline Type & Bus & $\mathbf{P}_{\mathbf{L}}(\mathbf{M W})$ & $\mathbf{Q}_{\mathbf{L}}(\mathbf{M v a r})$ \\
\hline Linear load & 1 & 7.6517 & 1.1607 \\
Linear load & 2 & 0.4523 & 0.2003 \\
Nonlinear load & 3 & 0.7124 & 0.3115 \\
\hline Motorized load & Bus & Parameter & Value \\
\hline & & Nominal power & $0.6 \mathrm{MVA}$ \\
& & Nominal voltage & $4160 \mathrm{~V}$ \\
& & Stator resistance & $0.019 \mathrm{pu}$ \\
& 4 & Stator inductance & $0.06 \mathrm{pu}$ \\
& & Rotor resistance & $0.019 \mathrm{pu}$ \\
& & Rotor inductance & $0.06 \mathrm{pu}$ \\
\hline \hline
\end{tabular}

TABLE IV

TECHNICAL DATA OF TRANSMISSION SYSTEM

\begin{tabular}{cc}
\hline \hline Parameters & Values \\
\hline Maximum short-circuit power & $249 \mathrm{MVA}$ \\
Minimum short-circuit power & $228 \mathrm{MVA}$ \\
Maximum $\mathrm{R} / \mathrm{X}$ ratio & 0.1 \\
Maximum $\mathrm{Z}_{2} / \mathrm{Z}_{1}$ ratio & 1 \\
Maximum $\mathrm{X}_{0} / \mathrm{X}_{1}$ ratio & 1 \\
Maximum $\mathrm{R}_{0} / \mathrm{X}_{0}$ ratio & 0.1 \\
\hline \hline
\end{tabular}

\section{Simulation Results of the System under Study: The Uncompensated System}

A simulation study was carried out using ETAP software. Table $\mathrm{V}$ gives the individual harmonic distortion as a percentage of the fundamental value. Also, the voltage total harmonic distortion (VTHD) at the different buses are provided.

For comparison purposes, Table VI presents the IEEE Standard 519-2014 limits [14].

TABLE V

INDIVIDUAL VOLTAGE HARMONIC LEVELS AND THE VTHD AT DIFFERENT BUSES BEFORE COMPENSATION

\begin{tabular}{ccccc}
\hline \hline \multirow{2}{*}{$\begin{array}{c}\text { Harmonic } \\
\text { order }\end{array}$} & \multicolumn{4}{c}{ \% Voltage harmonic level } \\
\cline { 2 - 5 } & Bus 1 & Bus 2 & Bus 3 & Bus 4 \\
\hline 5 & 23.06 & 23.04 & 23.03 & 23.01 \\
7 & 10.27 & 10.26 & 10.26 & 10.25 \\
11 & 8.21 & 8.22 & 8.22 & 8.22 \\
13 & 3.25 & 3.23 & 3.22 & 3.21 \\
17 & 4.20 & 4.19 & 4.19 & 4.19 \\
19 & 3.36 & 2.43 & 3.36 & 3.36 \\
23 & 2.85 & 2.85 & 2.85 & 2.85 \\
25 & 1.76 & 1.77 & 1.78 & 1.78 \\
VTHD $(\%)$ & 27.50 & 27.48 & 27.47 & 27.45 \\
\hline \hline
\end{tabular}

TABLE VI

IEEE STD. 519-2014 LIMITS [14]

\begin{tabular}{ccc}
\hline \hline Voltage level (kV) & $\begin{array}{c}\text { Individual } \\
\text { Harmonic } \\
\text { distortion }(\%)\end{array}$ & $\begin{array}{c}\text { Total harmonic } \\
\text { distortion, THD (\%) }\end{array}$ \\
\hline$V \leq 1.0 \mathrm{kV}$ & 5.0 & 8.0 \\
$1 \mathrm{kV}<V \leq 69 \mathrm{kV}$ & 3.0 & 5.0 \\
$69 \mathrm{kV}<V \leq 161 \mathrm{kV}$ & 1.5 & 2.5 \\
$161 \mathrm{kV}<V$ & 1.0 & 1.5 \\
\hline \hline
\end{tabular}

From the data provided in Tables V and VI, one can observe that there are harmonic levels that do not comply with the permissible standard limits.

\section{Simulation Results of the Compensated System using the Single-tuned Filter Scheme}

Four simulation studies were carried out using ETAP software for the system results with the single-tuned filter connected. Case 1 represents the filter design to mitigate the distortion of one harmonic order, i.e. the 5th harmonic, Case 2 represents the filter design to mitigate distortions of two harmonic orders, i.e. the 5th and the 11th harmonic orders, Case 3 represents the same but for mitigating the distortions of three harmonic orders, i.e. the 5th, 7th, and the 11th harmonic orders, and finally Case 4 represents the filter design to mitigate the distortions of four harmonic orders, i.e. 5th, 7th, 11th, and 17 th harmonic orders.

\section{VI.1. Case 1: Single-tuned filter for mitigating the 5th harmonic order}

The designed filter parameters are given in Table VII. Furthermore, Table VIII shows the individual harmonic level as a percentage of the fundamental value and the VTHD percentage at the different buses. 
TABLE VII

SINGLE-TUNED FILTER RESULTS: CASE 1

\begin{tabular}{|c|c|c|c|c|}
\hline \multicolumn{2}{|c|}{ Parameters } & & \multicolumn{2}{|c|}{ Designed values } \\
\hline \multicolumn{2}{|c|}{$\mathrm{C}_{S}(\mu \mathrm{F})$} & & \multicolumn{2}{|c|}{18.0214} \\
\hline \multicolumn{2}{|c|}{$L_{S}(\mathrm{mH})$} & & \multicolumn{2}{|c|}{22.489} \\
\hline \multicolumn{2}{|c|}{$R_{S}(\Omega)$} & & \multicolumn{2}{|c|}{0.3532} \\
\hline \multicolumn{5}{|c|}{$\begin{array}{c}\text { TABLE VIII } \\
\text { INDIVIDUAL VOLTAGE HARMONIC LEVELS AND THE \%VTHD } \\
\text { AT THE DIFFERENT BUSES WITH THE SINGLE-TUNED } \\
\text { FILTER: CASE } 1\end{array}$} \\
\hline \multirow{2}{*}{$\begin{array}{c}\text { Harmonic } \\
\text { order }\end{array}$} & \multicolumn{4}{|c|}{$\%$ Voltage harmonic level } \\
\hline & Bus 1 & Bus 2 & Bus 3 & Bus 4 \\
\hline 5 & 0.09 & 0.09 & 0.09 & 0.09 \\
\hline 7 & 5.66 & 5.65 & 5.65 & 5.64 \\
\hline 11 & 5.90 & 5.90 & 5.91 & 5.90 \\
\hline 13 & 2.64 & 2.44 & 2.42 & 2.42 \\
\hline 17 & 3.43 & 3.43 & 3.43 & 3.42 \\
\hline 19 & 2.40 & 2.39 & 2.39 & 2.39 \\
\hline 23 & 2.98 & 3.00 & 3.01 & 3.01 \\
\hline 25 & 1.55 & 1.55 & 1.55 & 1.55 \\
\hline VTHD (\%) & 10.1 & 10.1 & 10.1 & 10.09 \\
\hline
\end{tabular}

Table VIII provides that the 5th harmonic voltage level is reduced significantly from $23.06 \%$ to $0.09 \%$. However, there are still other individual harmonic levels and total harmonic distortion that are not within the standard levels of the IEEE Std. 519.

\section{VI.2. Case 2: Single-tuned filter for mitigating the 5th and the 11th harmonic orders}

The designed filter parameters for the two single-tuned filters are given in Table IX.

Furthermore, Table $\mathrm{X}$ shows the individual harmonic level as a percentage of the fundamental value and the VTHD percentage at the different buses.

Again, it is noted that both levels of the 5th and the 11th voltage harmonics are reduced significantly from $23.06 \%$ and $8.2 \%$ to $0.14 \%$ and $0.16 \%$, respectively. However, there are other individual voltages harmonic levels that are not within the standard levels of the IEEE Std. 519-2014. Also, the voltage total harmonic distortion does not comply with its permissible limit.

Accordingly, one more single-tuned filter branch may be needed as presented in Case 3 .

TABLE IX

SINGLE-TUNED FILTERS PARAMETERS: CASE 2

\begin{tabular}{ccc}
\hline \multirow{2}{*}{ Parameters } & \multicolumn{2}{c}{ Designed values } \\
\cline { 2 - 3 } & 5 th & 11 th \\
\hline $\mathrm{C}_{S}(\mu \mathrm{F})$ & 17.2574 & 0.7892 \\
$L_{S}(\mathrm{mH})$ & 23.4846 & 106.107 \\
$R_{S}(\Omega)$ & 0.3688 & 3.666 \\
\hline \hline
\end{tabular}

TABLE X

INDIVIDUAL VOLTAGE HARMONIC LEVELS AND THE \%VTHD AT THE DIFFERENT BUSES WITH THE SINGLE-TUNED FILTER: CASE 2

\begin{tabular}{ccccc}
\hline \hline \multirow{2}{*}{$\begin{array}{c}\text { Harmonic } \\
\text { order }\end{array}$} & \multicolumn{4}{c}{ \% Voltage harmonic level } \\
\cline { 2 - 5 } & Bus 1 & Bus 2 & Bus 3 & Bus 4 \\
\hline 5 & 0.14 & 0.14 & 0.14 & 0.14 \\
7 & 5.96 & 5.96 & 5.96 & 5.95 \\
11 & 0.16 & 0.18 & 0.19 & 0.19 \\
13 & 2.31 & 2.11 & 2.09 & 2.09 \\
17 & 3.25 & 3.24 & 3.24 & 3.24 \\
19 & 2.29 & 2.29 & 2.29 & 2.29 \\
23 & 2.89 & 2.91 & 2.92 & 2.92 \\
25 & 1.51 & 1.51 & 1.51 & 1.51 \\
VTHD (\%) & 8.18 & 8.18 & 8.17 & 8.17 \\
\hline \hline
\end{tabular}

\section{VI.3. Case 3: Single-tuned filter for mitigating the 5th, 7th, and the 11th harmonic orders}

The designed filter parameters for the three singletuned filters are given in Table XI.

TABLE XI

SINGLE-TUNED FILTERS PARAMETERS: CASE 3

\begin{tabular}{cccc}
\hline \hline \multirow{2}{*}{ Parameters } & \multicolumn{3}{c}{ Designed values } \\
\cline { 2 - 4 } & 5 th & 7 th & 11 th \\
\hline $\mathrm{C}_{S}(\mu \mathrm{F})$ & 10.1069 & 4.49 & 3.6302 \\
$L_{S}(\mathrm{mH})$ & 40.09 & 46.053 & 23.066 \\
$R_{S}(\Omega)$ & 0.6279 & 1.0127 & 0.7971 \\
\hline \hline
\end{tabular}

Table XII shows the individual harmonic level as a percentage of the fundamental value and the VTHD percentage at the different buses.

TABLE XII

INDIVIDUAL VOLTAGE HARMONIC LEVELS AND THE \%VTHD AT THE DIFFERENT BUSES WITH THE SINGLE-TUNED FILTER: CASE 3

\begin{tabular}{ccccc}
\hline \hline \multirow{2}{*}{$\begin{array}{c}\text { Harmonic } \\
\text { order }\end{array}$} & \multicolumn{4}{c}{ \% Voltage harmonic level } \\
\cline { 2 - 5 } & Bus 1 & Bus 2 & Bus 3 & Bus 4 \\
\hline 5 & 0.18 & 0.18 & 0.18 & 0.18 \\
7 & 0.08 & 0.08 & 0.08 & 0.07 \\
11 & 0.02 & 0.04 & 0.06 & 0.06 \\
13 & 1.34 & 1.31 & 1.29 & 1.29 \\
17 & 2.55 & 2.55 & 2.55 & 2.55 \\
19 & 1.88 & 1.88 & 1.88 & 1.88 \\
23 & 2.50 & 2.52 & 2.54 & 2.53 \\
25 & 1.31 & 1.31 & 1.31 & 1.30 \\
VTHD $(\%)$ & 4.49 & 4.50 & 4.50 & 4.50 \\
\hline \hline
\end{tabular}

As given in Table XII, all the individual harmonic levels, and the total harmonic distortion percentage are well-below the IEEE standard levels.

VI.4. Case 4: Single-tuned filter for mitigating the 5th, 7th, 11th, and the 17th harmonic orders 
The designed filter parameters for the four singletuned filters are given in Table XIII. Table XIV shows the individual harmonic level as a percentage of the fundamental value and the VTHD percentage at the different buses.

TABLE XIII

SINGLE-TUNED FILTERS PARAMETERS: CASE 4

\begin{tabular}{ccccc}
\hline \hline \multirow{2}{*}{ Parameters } & \multicolumn{5}{c}{ Designed values } \\
\cline { 2 - 5 } & 5th & 7th & 11 th & 13th \\
\hline \multirow{2}{*}{$\mathrm{C}_{S}(\mu \mathrm{F})$} & 9.20 & 4.08 & 3.29 & 1.68 \\
$L_{S}(\mathrm{mH})$ & 44.03 & 50.62 & 25.38 & 20.85 \\
$R_{S}(\Omega)$ & 0.69 & 1.11 & 0.87 & 1.11 \\
\hline \hline \multicolumn{5}{c}{ TABLE XIV } \\
INDIVIDUAL VOLTAGE HARMONIC LEVELS AND THE \%VTHD \\
AT THE DIFFERENT BUSES WITH THE SINGLE-TUNED \\
\multicolumn{5}{c}{ FILTER: CASE 4 } \\
\hline \hline Harmonic & \multicolumn{5}{c}{ \% Voltage harmonic level } \\
order & Bus 1 & Bus 2 & Bus 3 & Bus 4 \\
\hline 5 & 0.21 & 0.20 & 0.20 & 0.20 \\
7 & 0.08 & 0.08 & 0.08 & 0.08 \\
11 & 0.02 & 0.05 & 0.07 & 0.07 \\
13 & 1.79 & 1.77 & 1.75 & 1.75 \\
17 & 0.01 & 0.01 & 0.01 & 0.01 \\
19 & 1.02 & 1.02 & 1.02 & 1.01 \\
23 & 1.92 & 1.94 & 1.96 & 1.95 \\
25 & 1.07 & 1.05 & 1.05 & 1.04 \\
VTHD $(\%)$ & 3.06 & 3.06 & 3.06 & 3.06 \\
\hline \hline
\end{tabular}

Table XIV shows that the voltage harmonics are reduced significantly from $23.06 \%, 10.27 \%, 8.2 \%$, and $4.2 \%$ to $0.21 \%, 0.08 \%, 0.02 \%$, and $0.01 \%$, respectively.

\section{Simulation Results of the Compensated System using the Double-tuned Filter Scheme}

Two additional simulation studies were carried out using ETAP software for the system results with the double-tuned filter connected. Case 5 represents the filter design to mitigate distortions of two harmonic orders, i.e. the 5th and the 11th harmonic orders, while Case 6 represents the system with two double-tuned filters connected to mitigate distortions of four harmonic orders, i.e. 5 th, 11 th, and the 7 th, and 17 th harmonic orders.

\section{VII.1. Case 5: Double-tuned filter for mitigating the 5th, and the 11th harmonic orders}

The designed filter parameters for the double-tuned filters are given in Table XV. Table XVI shows the individual harmonic level as a percentage of the fundamental value and the VTHD percentage at the different buses.
TABLE XV

DOUBLE-TUNED FILTER PARAMETERS: CASE 5

\begin{tabular}{cc}
\hline \hline Parameters & Designed values \\
\hline$C_{\mathrm{S}}(\mu \mathrm{F})$ & 18.0465 \\
$L_{\mathrm{S}}(\mathrm{mH})$ & 19.228 \\
$C_{\mathrm{P}}(\mu \mathrm{F})$ & 39.9129 \\
$L_{\mathrm{P}}(\mathrm{mH})$ & 2.4502 \\
\hline
\end{tabular}

TABLE XVI

INDIVIDUAL VOLTAGE HARMONIC LEVELS AND THE \%VTHD AT THE DIFFERENT BUSES WITH THE DOUBLE-TUNED FILTER: CASE 5

\begin{tabular}{ccccc}
\hline \hline \multirow{2}{*}{$\begin{array}{c}\text { Harmonic } \\
\text { order }\end{array}$} & \multicolumn{4}{c}{ \% Voltage harmonic level } \\
\cline { 2 - 5 } & Bus 1 & Bus 2 & Bus 3 & Bus 4 \\
\hline 5 & 0.49 & 0.49 & 0.48 & 0.47 \\
7 & 5.95 & 5.94 & 5.94 & 5.94 \\
11 & 0.43 & 0.45 & 0.46 & 0.46 \\
13 & 2.12 & 2.09 & 2.08 & 2.08 \\
17 & 3.22 & 3.22 & 3.22 & 3.21 \\
19 & 1.02 & 1.02 & 1.02 & 1.01 \\
23 & 2.86 & 2.88 & 2.90 & 2.90 \\
25 & 1.43 & 1.44 & 1.44 & 1.43 \\
VTHD $(\%)$ & 8.17 & 8.16 & 8.16 & 8.16 \\
\hline \hline
\end{tabular}

From the results presented in Tables XVI, one can see that both voltage levels of the 5th and the 11th harmonic orders are reduced significantly from $23.06 \%$ and $8.2 \%$ to $0.49 \%$ and $0.43 \%$, respectively. Also, one can observe that the double-tuned filter can be designed to eliminate two dominant harmonic orders. However, there are other individual harmonic levels and total harmonic distortion that are not within the standard levels.

VII.2. Case 6: Double-tuned filter for mitigating the 5th, 11th, and the 7th, 17th harmonic orders

The designed filter parameters for the two doubletuned filters are given in Table XVII.

TABLE XVII

DOUBLE-TUNED FILTER PARAMETERS: CASE 6

\begin{tabular}{ccc}
\hline \hline & \multicolumn{2}{c}{ Designed values } \\
\cline { 2 - 3 } Parameters & 5th \&11th & 7th \&17th \\
\hline$C_{\mathrm{S}}(\mu \mathrm{F})$ & 12.5037 & 5.7658 \\
$L_{\mathrm{S}}(\mathrm{mH})$ & 16.100 & 14.769 \\
$C_{\mathrm{P}}(\mu \mathrm{F})$ & 17.694 & 6.869 \\
$L_{\mathrm{P}}(\mathrm{mH})$ & 9.5263 & 12.3919 \\
\hline \hline
\end{tabular}

Table XVIII shows the individual harmonic level as a percentage of the fundamental value and the VTHD percentage at the different buses. Table XVIII shows that all individual harmonic levels and the total harmonic distortion percentage become well below the standard levels with the two double-tuned filters connected. 
TABLE XVIII

INDIVIDUAL VOLTAGE HARMONIC LEVELS AND THE \%VTHD AT THE DIFFERENT BUSES WITH THE DOUBLE-TUNED FILTER: CASE 6

\begin{tabular}{ccccc}
\hline \hline \multirow{2}{*}{$\begin{array}{c}\text { Harmonic } \\
\text { order }\end{array}$} & \multicolumn{4}{c}{ \% Voltage harmonic level } \\
\cline { 2 - 5 } & Bus 1 & Bus 2 & Bus 3 & Bus 4 \\
\hline 5 & 0.54 & 0.54 & 0.53 & 0.53 \\
7 & 0.29 & 0.29 & 0.28 & 0.27 \\
11 & 0.37 & 0.38 & 0.39 & 0.39 \\
13 & 1.76 & 1.74 & 1.72 & 1.72 \\
17 & 0.29 & 0.29 & 0.29 & 0.29 \\
19 & 1.03 & 1.02 & 1.02 & 1.01 \\
23 & 1.88 & 1.90 & 1.92 & 1.92 \\
25 & 1.06 & 1.05 & 1.04 & 1.04 \\
VTHD $(\%)$ & 3.10 & 3.10 & 3.11 & 3.10 \\
\hline \hline
\end{tabular}

It is demonstrated that two double-tuned filters can be used instead of using four single-tuned filters under the same conditions, while having a similar performance in minimizing both individual harmonic and total harmonic distortion levels. Keeping in mind the higher power losses, the larger size, and the increased cost of the multiple-arm single-tuned filters compared to the doubletuned filter; therefore, utilizing of the double-tuned filter is more reliable than the single-tuned passive filter type.

\section{Implementation Considerations in Practice}

All loads should work at reasonable power factors. This ensures service continuity and good service quality for consumers as the probability of service interruption is more with low power factor loads. Therefore, applying power factor correction capacitors or shunt passive filters requires special considerations concerning harmonics to avoid capacitor failures because of harmonic resonance. Accordingly, the resonant frequencies should be safely away from any significant harmonic orders.

Ignoring the harmonic resonance in the analysis would lead to inaccurate results. In practice, filters are tuned slightly lower than the harmonic to be filtered. This is to provide a safety margin in case there are changes in parameters of the system. Besides, filters are added to the system starting with the lowest significant harmonic orders found in the system to avoid this problem with this resonance [18].

Finally, filters should be designed with the capacity of the bus in mind. The popular appeal is to size the currentcarrying capacity based solely on the load that is producing harmonics. However, a small amount of background voltage distortion on a bus may impose an excessive duty on the filter. Hence, based on IEEE Standard 18-2012 [19]; capacitors are capable of safe, and continuous operation provided not to exceed $135 \%$ of the nominal rms current, $110 \%$ of the nominal rms voltage, and $135 \%$ of the nominal kvar. Compliance with these guidelines is imperative for capacitor as they are voltage-sensitive components of passive filters. The filters that do not follow these conditions may suffer from high costs; also, their unreliable operation may be expected.

\section{Conclusion}

This paper presents a harmonic mitigation study in grid-connected solar PV system using both single-tuned and double-tuned filters, while investigating and analyzing their performances. The simulation results in the ETAP environment shows that the double-tuned filters give better performances compared to the singletuned filters under the same non-sinusoidal conditions. The single-tuned filter can only attenuate a particular harmonic frequency, while the double-tuned filter can efficiently attenuate two harmonic frequencies at once. Further, the single-tuned filter has some drawbacks such as the higher power losses, larger size, and the high operating costs compared to the double-tuned filter. However, both filter types are well performing in service, and they are considered maintenance and trouble free for years. Finally, the performance and effectiveness of the proposed shunt passive filters were verified by the various simulation results presented, and it is evident that harmonics mitigation with double-tuned filters is more economically viable compared to the single-tuned filter.

\section{References}

[1] A.F. Zobaa, R.C. Bansal, Handbook of Renewable Energy Technology (World Scientific Publishing Co. Pte. Ltd., $1^{\text {st }}$ edition, 2011).

[2] Ahmed G. E. Mousa, Shady H. E. Abdel Aleem, Ahmed M. Ibrahim, Mathematical Analysis of Maximum Power Points and Currents Based Maximum Power Point Tracking in Solar Photovoltaic System: A Solar Powered Water Pump Application, International Review of Electrical Engineering, vol. 11, January-February 2016, pp. 97-108. http://dx.doi.org/10.15866/iree.v11i1.8137

[3] P. Meier, M. Vagliasindi, M. Imran, A. Eberhard, T. Siyambalapitiya, The Design and Sustainability of Renewable Energy Incentives: An Economic Analysis (Energy and mining. Washington, DC: World Bank Publications, October 29, 2014).

[4] S. Sakar, M. E. Balci, S. H. E. A. Aleem and A. F. Zobaa, "Hosting capacity assessment and improvement for photovoltaicbased distributed generation in distorted distribution networks," 2016 IEEE 16th International Conference on Environment and Electrical Engineering (EEEIC), Florence, 2016, pp. 1-6. doi: 10.1109/EEEIC.2016.7555515

[5] A. C. Köberle, D. E. H. J. Gernaat, D. P. V. Vuuren, Assessing current and future techno-economic potential of concentrated solar power and photovoltaic electricity generation. Energy, vol. 89, 2015, pp. 739-756. http://dx.doi.org/10.1016/j.energy.2015.05.145

[6] Yew W. Kean, P. S. Yong, A. Ramasamy, V. K. Ramachandaramurthy, Comparison of the Effect of Filter Design on the Total Harmonic Distortion in Three-Phase Stand-Alone Photovoltaic System, ARPN Journal of Engineering and Applied Sciences, vol. 10, n. 21, November 2015, pp. 9919-9925.

[7] Shady H. E. Abdel Aleem, A.F. Zobaa, Optimal C-type filter for harmonics mitigation and resonance damping in industrial distribution systems. Electr Eng. 2016, In press. doi:10.1007/s00202-016-0406-1 
[8] S. V. S. Kumary, V. A. A. M. T. Oo, G. M. Shafiullah and A. Stojcevski, "Modelling and power quality analysis of a gridconnected solar PV system," Power Engineering Conference (AUPEC), 2014 Australasian Universities, Perth, WA, 2014, pp. 1-6. doi: 10.1109/AUPEC.2014.6966605

[9] S Sakar, A. D. Karaoglan, M. E. Balci, S. H. E. A. Aleem, A. F. Zobaa, Optimal Design of Single-Tuned Passive Filters Using Response Surface Methodology, The International School on Nonsinusoidal Currents and Compensation ISNCC 2015 , June 15-18, 2015, Lagow, Poland. http://dx.doi.org/10.1109/ISNCC.2015.7174709

[10] M. Tali, A. Obbadi, A. Elfajri and Y. Errami, "Passive filter for harmonics mitigation in standalone PV system for non linear load," 2014 International Renewable and Sustainable Energy Conference (IRSEC), Ouarzazate, 2014, pp. 499-504. doi: 10.1109/IRSEC.2014.7059834

[11] B. H. Yong and V. K. Ramachandaramurthy, "Double Tuned filter design for harmonic mitigation in grid connected solar PV," Power and Energy (PECon), 2014 IEEE International Conference on, Kuching, 2014, pp. 293-297. doi: 10.1109/PECON.2014.7062459

[12] J. C. Das, Power System Harmonics and Passive Filter Designs (Wiley-IEEE Press, 1st edition, 2015).

[13] M. A. Zamani and M. Mohseni, "Damped-type double tuned filters design for HVDC systems," 2007 9th International Conference on Electrical Power Quality and Utilisation, Barcelona, 2007

pp.

$1-6$. doi: 10.1109/EPQU.2007.4424205

[14] IEEE Recommended Practice and Requirements for Harmonic Control in Electric Power System, IEEE Power and Energy Society, 1EEE Std 519-2014, USA.

[15] Young-Si Cho, Hanju Cha, Single-tuned Passive Harmonic Filter Design Consideration Variances of Tuning and Quality Factor, The Journal of International Council on Electrical Engineering (ICEE) vol. 1, n. 1, January 2011, pp. 7-13. doi: http://dx.doi.org/10.5370/JICEE.2011.1.1.007

[16] H.E. Yi-hong, S.U. Heng, A New Method of Designing Doubletuned Filter, Proc. of the 2nd International Conference on Computer Science and Electronics Engineering (ICCSEE 2013), January 2013, pp. 206-209.

[17] Renewables Academy (RENAC) AG, Photovoltaic based energy farming in Jordan: Sample plant and system design for gridconnected PV systems, Berlin, Germany, March 2013.

[18] A. F. Zobaa, M. M. Abdel-Aziz, S. H. E. Abdel Aleem, Comparison of shunt-passive and series-passive filters for DC drive loads, Electric Power Components \& Systems, vol. 38, no. 3, Mar. 2010. pp. 275-291. doi: http://dx.doi.org/10.1080/15325000903273262

[19] IEEE Standard for Shunt Power Capacitors, IEEE Standard 182012, 2012, USA.

\section{Authors' information}

${ }^{1}$ College of Engineering, Design and Physical Sciences Department of Electronic and Computer Engineering, Brunel University London, Uxbridge, UB8 3PH, Middlesex, United Kingdom.

${ }^{2} 15$ th of May Higher Institute of Engineering, $15^{\text {th }}$ of May City, Cairo, Egypt.

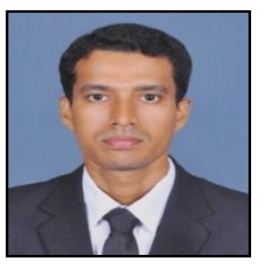

Murukwadura A. Mendis graduated with first degree in Electrical and Electronic Engineering from Kotalawala Defence University and PG Dip. in Electrical Installation from University of Moratuwa, Sri Lanka in 2007 and 2012 respectively. He is currently pursuing MSc. degree in Sustainable Electrical Power in the Department of
Electronic and Computer Engineering, Brunel University London. His employment experience includes electromechanical engineering and electrical installation engineering.

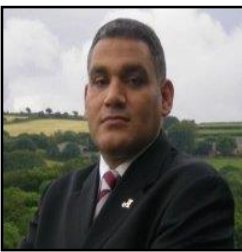

Ahmed F. Zobaa received the B.Sc.(Hons), M.Sc., and Ph.D. degrees in electrical power and machines from Cairo University, Egypt, in 1992, 1997, and 2002, respectively. From 2007 to 2010, he was a Senior Lecturer in renewable energy at University of Exeter, U.K. He was also an Instructor from 1992 to 1997, a Teaching Assistant from 1997 to 2002, an Assistant Professor from 2003 to 2008, an Associate Professor from 2008 to 2013 at Cairo University where he has also been a Professor (on leave) since December 2013. Currently, he is a Senior Lecturer in power systems, an MSc Course Director and a Full Member of the Institute of Energy Futures at Brunel University London, U.K. His main areas of expertise are power quality, (marine) renewable energy, smart grids, energy efficiency, and lighting applications.

Dr. Zobaa is an Editor-in-Chief for the International Journal of Renewable Energy Technology and Technology and Economics of Smart Grids and Sustainable Energy. He is also an Editorial Board member, Editor, Associate Editor, and Editorial Advisory Board member for many international journals. He is a registered Chartered Engineer, Chartered Energy Engineer, European Engineer, and International Professional Engineer. He is also a registered member of the Engineering Council U.K., Egypt Syndicate of Engineers, and the Egyptian Society of Engineers. He is a Senior Fellow of the Higher Education Academy of U.K. He is a Fellow of the Institution of Engineering and Technology, the Energy Institute of U.K., the Chartered Institution of Building Services Engineers, the Institution of Mechanical Engineers, the Royal Society of Arts, the African Academy of Science, and the Chartered Institute of Educational Assessors. He is a senior member of the Institute of Electrical and Electronics Engineers. Also, he is a member of the International Solar Energy Society, the European Power Electronics and Drives Association, and the IEEE Standards Association.

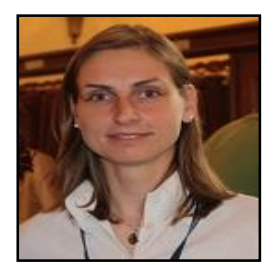

Ioana Pisica is lecturer in Power Systems at Brunel University London, Department of Electronic and Computer Engineering. She received her MSc in Information Systems from the Academy of Economic Studies from Bucharest and her $\mathrm{PhD}$ from University Politehnica of Bucharest. Her research interests include modern optimization techniques for power systems with distributed generation and FACTS devices, machine learning for power systems control, power quality, smart metering and ICT infrastructures for future power networks.

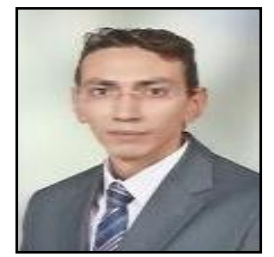

Shady H. E. Abdel Aleem received the B.Sc. and M.Sc. and Ph.D. degrees in Electrical Power and Machines from the Faculty of Engineering, Helwan University, Helwan, Egypt, in 2002, and the Faculty of Engineering, Cairo University, Egypt, in 2010 and 2013 respectively. Currently, he is a Assistant Professor at $15^{\text {th }}$ of May Higher Institute of Engineering. $\mathrm{He}$ is working in the field of electric machines, power quality, electric circuits, and engineering mechanics. Dr. Shady is a member of the Institute of Electrical and Electronics Engineers. He regularly reviews papers for many IEEE Transactions and journals in his areas of interest. Dr. Shady is author or co-author of many journal and conference papers. Areas of research include harmonic problems in power systems, power quality, solar energy, wind energy, green energy, electric machines, distributed generation, economics and engineering mechanics. 